\title{
Association study for single nucleotide polymorphisms in the CYP17A1 gene and polycystic ovary syndrome
}

\author{
JUNG-MI PARK ${ }^{1}$, EUNG-JI LEE ${ }^{1}$, SURESH RAMAKRISHNA ${ }^{1}$, DONG-HYUN CHA ${ }^{2}$ and KWANG-HYUN BAEK ${ }^{1}$ \\ ${ }^{1}$ Graduate School of Life Science and Biotechnology, Cell and Gene Therapy Research \\ Institute, Pochon CHA University, CHA General Hospital; ${ }^{2}$ Division of \\ Gynecology and Obstetrics, Pochon CHA University, Seoul 135-081, Korea
}

Received March 14, 2008; Accepted May 12, 2008

DOI: 10.3892/ijmm_00000016

\begin{abstract}
Women with polycystic ovary syndrome (PCOS) are characterized by excess androgen secretion and anovulatory infertility as a cause of follicular maturation arrest, and they are also associated with insulin resistance and obesity. Recently, it was suggested that one of the etiologies for PCOS is an abnormality of steroid hormones, and excessive secretion of androgen. The endoplasmic reticular cytochrome P450, 17 $\alpha$-hydroxylase (CYP17A), plays a key role in the mechanism of steroid hormones such as adrenal and gonadal steroid biosynthesis. Therefore, we studied the association between single nucleotide polymorphisms (SNPs) of the $A l$ allelic variant of the $C Y P 17$ gene and PCOS in a Korean population. The study recruited 134 Korean women with PCOS and 100 healthy women as controls. Using the HapAnalyzer, the genotype of the CYP17Al polymorphism in PCOS and control patients were analyzed. We considered a p-value lower than 0.05 to be statistically significant. After genotypic analysis, we found seven SNPs of the CYP17Al gene in a large population of subjects. The frequency of seven SNPs had no significant association with PCOS. However, one haplotype (ht 3 ) had a p-value of $\mathrm{p}=0.001$, suggesting that it may be associated with the pathogenesis of PCOS in a Korean population.
\end{abstract}

\section{Introduction}

Polycystic ovary syndrome (PCOS) is one of the most common endocrine disorders occurring in 4-12\% of women of reproductive age $(1,2)$. According to a previous study, $4.9 \%$ of female college students in Korea manifested PCOS (3). Women with PCOS represent various phenotypes such as

Correspondence to: Dr Kwang-Hyun Baek, Cell and Gene Therapy Research Institute, Pochon CHA University, CHA General Hospital, 606-16 Yeoksam 1-Dong, Kangnam-Gu, Seoul 135-081, Korea

E-mail: baek@cha.ac.kr

Key words: polycystic ovary syndrome, single nucleotide polymorphism, $17 \alpha$-hydroxylase-17,20-lyase polycystic ovary morphology, obesity, hyperandrogenism, and anovulation infertility (6-8). Many metabolic abnormalities of PCOS lead to metabolic syndromes such as type 2 diabetes mellitus, dyslipidemia, and hypertension in postmenopausal women with PCOS $(9,10)$.

Insulin production, excessive secretion of androgen, ovarian steroidogenic response to luteinizing hormone (LH), and FSH levels have been suggested to affect cyst formation in ovarian follicles (11). Furthermore, a recent study showed that insulin and insulin receptor (INSR) genes play a key role as genetic factors for the pathogenesis of PCOS $(11,12)$. Previous reports showed that the Pro12Ala variant of $P P A R \gamma$ and the single nucleotide polymorphisms (SNP) of the $V E G F$ gene are also important components in the pathogenesis of PCOS $(13,14)$.

Since women with PCOS are characterized by excess androgen secretion and anovulatory infertility as a cause of follicular maturation arrest, patients with PCOS are associated with insulin resistance and obesity (15). Several mechanisms involved in steroid hormone synthesis have been reported in the etiology of PCOS $(16,17)$. Steroid hormone synthesis pathway is associated with the regulation of androgens, insulin signaling and obesity (17). The etiology of PCOS is involved in metabolic and/or regulatory pathway of steroid hormones, including LH and testosterone (18). Recently, it was suggested that one of the etiologies for PCOS is an abnormality of steroid hormones, and excessive androgen secretion $(17,18)$.

A number of SNP studies suggested that the dysregulatory steroidogenic enzyme $\mathrm{P} 45 \mathrm{c} 17 \alpha$ may be critically related to the etiology of hyperandrogenism in PCOS. Steroid hormones are produced from cholesterol via CYP enzymes such as CYP11A, CYP11B1, CYP11B2, CYP17, CYP19, and CYP21. One of the CYP enzymes causing hyperandrogenism is encoded by $17 \alpha$-hydroxylase-17,20-lyase (CYP17) located on chromosome 10q24-q25. The endoplasmic reticular cytochrome P450, 17 $\alpha$-hydroxylase, plays a key role in the mechanism of steroid hormones such as adrenal and gonadal steroid biosynthesis (19). CYP17 is a key enzyme in the steroidogenic pathway and is known to produce progestins, mineralocorticoids, glucocorticoids, androgens, and estrogens. SNPs of $C Y P 17$ are associated with several diseases including PCOS, breast cancer, Cushing's syndrome, and prostate cancer in different ethnic groups (20). Two alleles of CYP17 changed from thymine (T) to cytosine (C) at -34 bp are 
denoted as $A 1$ allele and $A 2$ allele, respectively (19). The CYP17Al gene encodes a member of the cytochrome P450 superfamily of enzymes.

Recently, numerous SNPs have been investigated by association studies in PCOS patients. One of the SNPs involved in steroidogenic alteration leads to an adrenal hyperandrogenism in PCOS patients $(22,23)$. The CYP1la gene is a candidate gene for abnormal steroidogenesis and the P450 side chain cleavage enzyme of cholesterol. A microsatellite polymorphism (tttta) $)_{\mathrm{n}}$ of CYP11a located at $528 \mathrm{bp}$ upstream from the initiation site of the translation, which encodes cytochrome P450scc, is associated with both PCOS and testosterone level (24). It has been reported that the frequency of heterozygosity for $C Y P 21$ mutation in children with premature pubarche and in adolescent girls with hyperandrogenism is increased (25).

In the present study, we investigated the relationship between the pathogenesis of PCOS and several polymorphisms of the CYP17Al gene. The aim of this study was to identify whether the frequency of $7 \mathrm{SNPs}$ including $-600 C>A$, $-34 C>T,+723 G>A,+2612 T>C,+4259 C>T,+4444 C>G$, and $+4994 C>T$ in $C Y P 17 A 1$ is associated with PCOS in a Korean population.

\section{Materials and methods}

Subjects. For the purposes of this study we recruited 134 women diagnosed for PCOS based on the revised diagnostic criteria recommended in 2003 by the American Society for Reproductive Medicine/European Society for Human Reproduction and Embryology (ASRM/ESHRE) Rotterdam consensus $(4,5)$, and another 100 women with a similar body mass index (BMI). Blood samples were collected after 2-3 days of menstruation from both PCOS and the control groups in a Korean population for both biochemical assay and DNA sequencing analysis. All subjects were recruited from the Fertility Center at CHA General Hospital located in Seoul, Korea. Clinical and biochemical characteristics of women with PCOS and the control groups are shown in Table I. To determine their state of health state, we confirmed prior medical history, and carried out physical and pelvic examinations, and complete blood chemistry. Blood samples for molecular genetic analyses were collected in tubes containing EDTA as an anticoagulant and store at $4^{\circ} \mathrm{C}$ until use. All controls and patients in this study were Korean women. This SNP study using human blood samples was approved by the Institutional Review Board (IRB).

Clinical and biochemical determination. For the diagnostic criteria of women with PCOS, hyperandrogenism was defined as testosterone $(\mathrm{T})>0.6 \mathrm{ng} / \mathrm{ml}$ and/or serum DHEAS $\geq 300 \mu \mathrm{g} / \mathrm{dl}(21,22)$ and a reduction in the frequency of menstrual cycle between 40 days and 6 months. Clinical and biochemical characteristics of PCOS and control groups are given in Table I. In addition, other parameters were used such as plasma FSH, LH, TSH, DHEA-S, prolactin, and testosterone.

Sequencing analysis of human CYP17A1. All exons of CYP17A1 were sequenced to identify SNPs in 24 DNA samples from healthy Korean women using the ABI PRISM 3730 DNA Analyzer (Applied Biosystems, Foster City, CA, USA). Eleven primer sets for amplification and sequencing analysis were designed based on GeneBank (accession no.: NM_000102 and AC006106). Sequence variants were verified by chromatograms.

Genotyping with sequencing analysis. Amplifying primers and probes for genotyping of the polymorphic site were designed by TaqMan analysis. PCR primers and the MGB (minor groove binder) TaqMan probes were designed with Primer Express (Applied Biosystems). One allelic probe was labelled with FAM dye and the other with fluorescent VIC dye. PCRs were performed using TaqMan Universal Master mix without uracil-DNA glycosylase (UNG) (Applied Biosystems) with PCR primer concentration of $900 \mathrm{nM}$ and TaqMan MGB-probe concentration of $200 \mathrm{nM}$. A 384-well format in a total reaction volume of $5 \mu \mathrm{l}$ using $20 \mathrm{ng}$ of genomic DNA was used for reaction. The plate was placed on a thermal cycler (PE9700, Applied Biosystems), heated at $50^{\circ} \mathrm{C}$ for 2 min and $95^{\circ} \mathrm{C}$ for $10 \mathrm{~min}$ followed by 40 cycles of $95^{\circ} \mathrm{C}$ for $15 \mathrm{sec}$ and $60^{\circ} \mathrm{C}$ for $1 \mathrm{~min}$. The fluorescent intensity in each well of the plate was then read by a Prism $7900 \mathrm{HT}$ instrument (Applied Biosystems). Using automated software (SDS 2.1), fluorescent files for each well of the plate were analyzed.

Statistical and haplotype analyses. Using the HapAnalyzer (NGRI, Seoul, Korea; www.hap.ngri.re.kr), the genotypes of CYP17Al polymorphisms in PCOS and control patients were analyzed. We considered $\mathrm{p}<0.05$ statistically significant. To determine whether the haplotypes in the CYP17Al had association with PCOS, we analyzed those with SNPs using the HapAnalyzer. Several haplotypes and their frequencies were identified using the PL-EM program (Harvard, Boston, MA, USA; www.people.fas.harvard .edu/ junliu/plem/click. html). As a result, we obtained 5 haplotypes which had frequencies $>0.05$, and then performed an association test.

\section{Results}

To determine the frequency of the SNP genotypes in the CYP17A1 gene, we used TaqMan sequencing analysis for large scale genotyping, based on linkage disequilibrium (LD), location, allele frequency and haplotype-tagging status. In addition, the frequency of genotype for each SNP from PCOS patients $(n=134)$ and controls $(n=100)$ for this study was analysed using the TaqMan analysis program. The analyses revealed 7 SNPs in the $C Y P 17 A 1$ gene, $-600 C>A$, $-34 C>T,+723 G>A,+2612 T>C,+4259 C>T,+4444 C>G$ and $+4994 C>T$ in PCOS and control subjects (Fig. 1). However, a few samples were not taken into account because of sequencing errors.

For the diagnostic criteria of PCOS patients, we followed the guidelines defined by the ASRM/ESHRE Rotterdam consensus in $2003(4,5)$. The clinical and biochemical information of PCOS patients and normal control groups are shown in Table I and Fig. 2. Specific characteristics of PCOS include polycystic ovary, oligoamenorrhea, amenorrhea, hyperandrogenism and high levels of LH, DHEA-S and testosterone. Our study revealed that $\mathrm{LH}$ and testosterone levels in the 
Table I. Clinical and biochemical characteristics of patients for PCOS and control subjects.

\begin{tabular}{lcc}
\hline Characteristics & PCOS patient $(\mathrm{n}=134)$ & Normal control $(\mathrm{n}=100)$ \\
\hline BMI $\left(\mathrm{kg} / \mathrm{m}^{2}\right)$ & $23.22 \pm 3.88(16.18-37.32)$ & $20.73 \pm 2.36(16.61-27.70)$ \\
Waist/hip ratio $(\mathrm{WHR})$ & $0.81 \pm 0.09(0.67-1.49)$ & $0.80 \pm 0.07(0.71-0.91)$ \\
Obesity & $\mathrm{n}=33(24.63 \%)$ & $\mathrm{n}=5(5.00 \%)$ \\
FSH levels $(\mathrm{mIU} / \mathrm{ml})$ & $5.81 \pm 4.53(1.00-40.00)$ & $6.54 \pm 3.04(3.20-17.70)$ \\
LH levels $(\mathrm{mIU} / \mathrm{ml})$ & $8.37 \pm 6.45(1.00-39.00)$ & $3.24 \pm 1.48(1.12-7.10)$ \\
TSH levels $(\mu \mathrm{IU} / \mathrm{ml})$ & $2.28 \pm 1.15(0.62-5.47)$ & $2.28 \pm 1.17(0.30-5.38)$ \\
DHEA-S levels $(\mu \mathrm{g} / \mathrm{dl})$ & $199.10 \pm 77.50(57.50-377.20)$ & $157.86 \pm 64.22(56.70-300.00)$ \\
Prolactin levels $(\mathrm{ng} / \mathrm{ml})$ & $12.07 \pm 4.47(5.30-23.70)$ & $12.11 \pm 5.84(4.10-24.40)$ \\
Testosterone $(\mathrm{ng} / \mathrm{ml})$ & $0.68 \pm 0.56(0.10-3.71)$ & $0.28 \pm 0.13(0.10-0.80)$ \\
\hline
\end{tabular}

Table II. Frequencies of genotypes of the analyzed SNPs.

\begin{tabular}{|c|c|c|c|c|c|c|c|c|c|}
\hline \multirow[t]{2}{*}{ Loci } & \multirow[t]{2}{*}{ Genotype } & \multirow{2}{*}{$\begin{array}{c}\text { PCOS cases } \\
\mathrm{n}(\%)\end{array}$} & \multirow{2}{*}{$\begin{array}{l}\text { Control } \\
\mathrm{n}(\%)\end{array}$} & \multicolumn{2}{|c|}{ Co-dominant } & \multicolumn{2}{|c|}{ Dominant } & \multicolumn{2}{|l|}{ Recessive } \\
\hline & & & & OR $(95 \% \mathrm{CI})$ & $\mathrm{P}$ & OR $(95 \% \mathrm{CI})$ & $\mathrm{P}$ & OR $(95 \% \mathrm{CI})$ & $\mathrm{P}$ \\
\hline \multirow[t]{4}{*}{-600} & $\mathrm{CC}$ & $104(78.79 \%)$ & $81(81.82 \%)$ & $1.24(0.69-2.23)$ & 0.4759 & $1.21(0.63-2.34)$ & 0.5685 & $2.28(0.23-22.25)$ & 0.4785 \\
\hline & $\mathrm{CA}$ & $25(18.94 \%)$ & $17(17.17 \%)$ & & & & & & \\
\hline & AA & $3(2.27 \%)$ & $1(1.01 \%)$ & & & & & & \\
\hline & Total & 132 & 99 & \multicolumn{6}{|c|}{ OR $(95 \% \mathrm{CI})=1.25(0.69-2.29) ; \mathrm{p}=0.5595$} \\
\hline \multirow[t]{4}{*}{-34} & $\mathrm{CC}$ & $32(24.06 \%)$ & $33(33.33 \%)$ & $1.29(0.91-1.83)$ & 0.1571 & $1.58(0.89-2.81)$ & 0.1211 & $1.27(0.71-2.29)$ & 0.419 \\
\hline & $\mathrm{CT}$ & $61(45.86 \%)$ & $41(41.42 \%)$ & & & & & & \\
\hline & TT & $40(30.08 \%)$ & $25(25.25 \%)$ & & & & & & \\
\hline & Total & 133 & 99 & \multicolumn{6}{|c|}{ OR $(95 \% \mathrm{CI})=1.33(0.92-1.92) ; \mathrm{p}=0.1594$} \\
\hline \multirow[t]{4}{*}{+723} & GG & $33(24.63 \%)$ & $33(33.00 \%)$ & \multirow[t]{3}{*}{$1.25(0.88-1.78)$} & \multirow[t]{3}{*}{0.2062} & \multirow[t]{3}{*}{$1.51(0.85-2.67)$} & \multirow[t]{3}{*}{0.1603} & \multirow[t]{3}{*}{$1.23(0.69-2.21)$} & \multirow[t]{3}{*}{0.4863} \\
\hline & GA & $62(46.27 \%)$ & $42(42.00 \%)$ & & & & & & \\
\hline & AA & $39(29.10 \%)$ & $25(25.00 \%)$ & & & & & & \\
\hline & Total & 134 & 100 & \multicolumn{6}{|c|}{ OR $(95 \% \mathrm{CI})=1.28(0.89-1.85) ; \mathrm{p}=0.2144$} \\
\hline \multirow[t]{4}{*}{+2612} & TT & $64(48.12 \%)$ & $46(46.47 \%)$ & \multirow[t]{3}{*}{$1.03(0.71-1.50)$} & \multirow[t]{3}{*}{0.8694} & \multirow[t]{3}{*}{$0.94(0.56-1.58)$} & \multirow[t]{3}{*}{0.8028} & \multirow[t]{3}{*}{$1.33(0.60-2.95)$} & \multirow[t]{4}{*}{0.477} \\
\hline & $\mathrm{TC}$ & $50(37.59 \%)$ & $42(42.42 \%)$ & & & & & & \\
\hline & $\mathrm{CC}$ & $19(14.29 \%)$ & $11(11.11 \%)$ & & & & & & \\
\hline & Total & 133 & 99 & & OR ( & $5 \% \mathrm{CI})=1.04(0.70$ & $1.53) ; \mathrm{p}=($ & .9423 & \\
\hline \multirow[t]{4}{*}{+4259} & $\mathrm{CC}$ & $131(99.24 \%)$ & $100(100.0 \%)$ & \multirow[t]{3}{*}{ N/A } & \multirow[t]{3}{*}{0.9983} & N/A & 0.9983 & $\mathrm{~N} / \mathrm{A}$ & N/A \\
\hline & CT & $1 \quad(0.76 \%)$ & $0 \quad(0.00 \%)$ & & & & & & \\
\hline & TT & $0(0.00 \%)$ & $0 \quad(0.00 \%)$ & & & & & & \\
\hline & Total & 132 & 100 & & & $\mathrm{~N} / \mathrm{A} ; \mathrm{p}=0.99$ & & & \\
\hline+4444 & $\mathrm{CC}$ & $49(36.84 \%)$ & $44(44.00 \%)$ & $1.18(0.83-1.70)$ & 0.354 & $1.35(0.79-2.29)$ & 0.27 & $1.13(0.57-2.23)$ & 0.724 \\
\hline & $\mathrm{CG}$ & $59(44.36 \%)$ & $39(39.00 \%)$ & & & & & & \\
\hline & GG & $25(18.80 \%)$ & $17(17.00 \%)$ & & & & & & \\
\hline & Total & 133 & 100 & & $\mathrm{OR}(\mathrm{C}$ & $\% \mathrm{CI})=1.21(0.83-$ & $.76) ; p=0$ & .3764 & \\
\hline+4994 & $\mathrm{CC}$ & $84(62.69 \%)$ & $65(65.00 \%)$ & $1.15(0.73-1.82)$ & 0.5483 & $1.11(0.64-1.90)$ & 0.7159 & $1.78(0.45-7.07)$ & 0.4112 \\
\hline & $\mathrm{CT}$ & $43(32.09 \%)$ & $32(32.00 \%)$ & & & & & & \\
\hline & $\mathrm{TT}$ & $7 \quad(5.22 \%)$ & $3 \quad(3.00 \%)$ & & & & & & \\
\hline & Total & 134 & 100 & & OR & $5 \% \mathrm{CI})=1.15(0.73$ & 1.82); $\mathrm{p}=$ & 0.626 & \\
\hline
\end{tabular}

PCOS group are two times higher than those of the control group. In addition, DHEA-S levels of the PCOS group were slightly higher than those of the control group. Although 5\% of subjects were obese and/or had an irregular menstrual cycle and $2 \%$ of subjects had polycystic ovary in a control group, $93 \%$ of subjects of the same group showed no PCOS symptoms. 


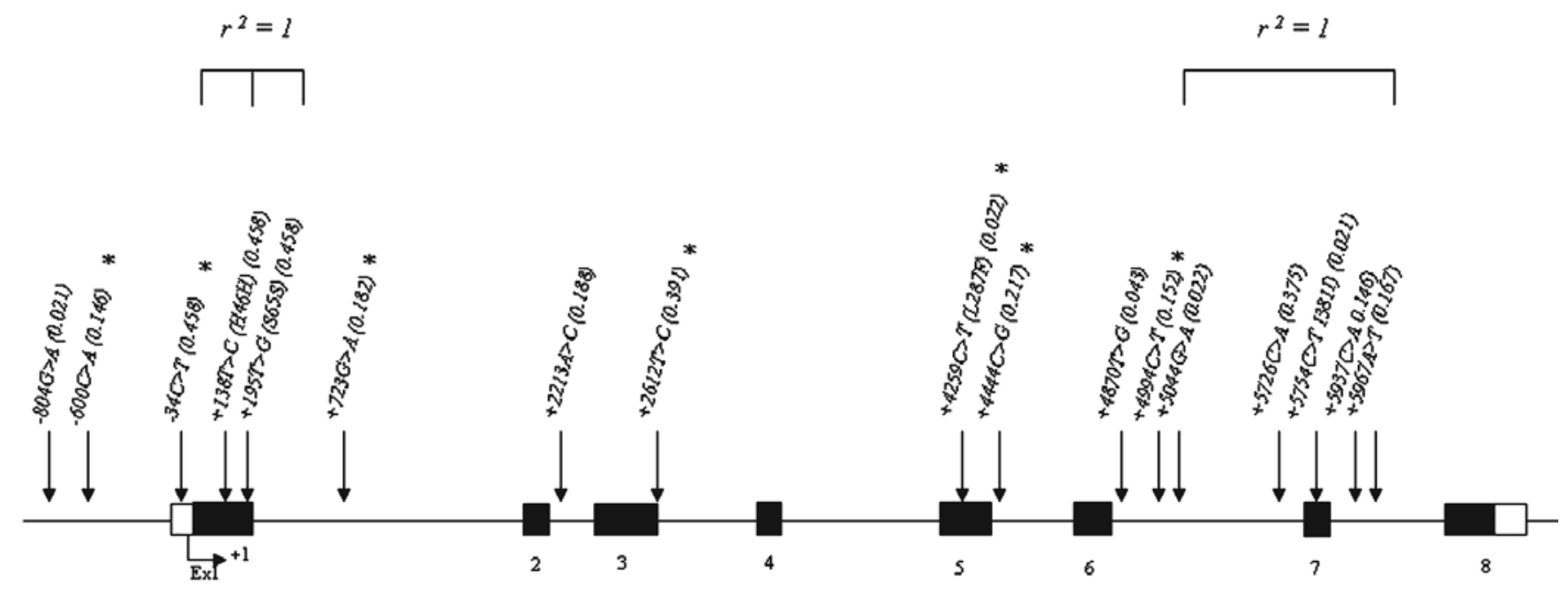

Figure 1. Map of CYP17Al on chromosome 10q24.3 (7 kb). The black blocks indicate the coding exons and the white blocks indicate 5' and 3' UTR. 'Seven sites of SNPs were genotyped in a large Korean population.

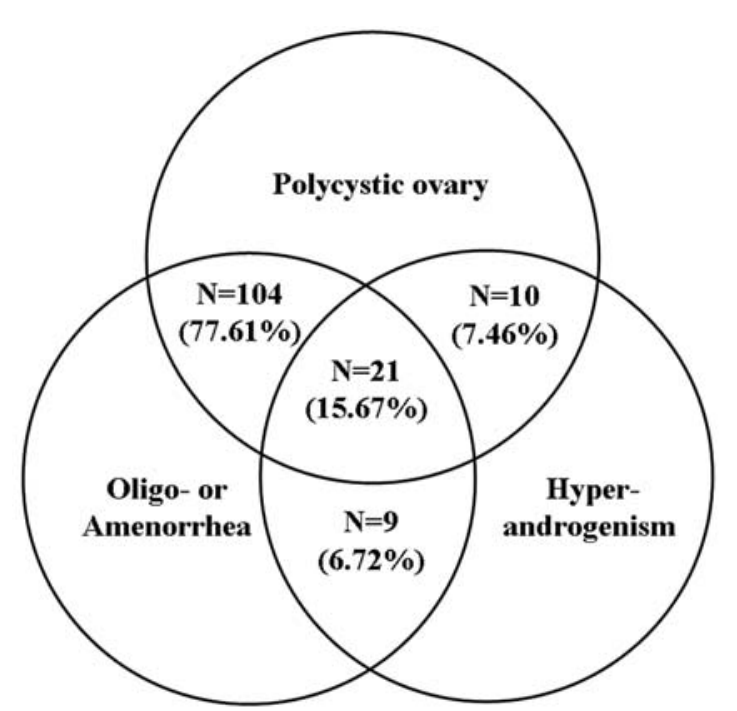

Figure 2. Diagnostic criteria for PCOS include 3 symptoms, oligomenorrhea or amenorrhea, hyperandrogenism, and polycystic ovary (PCO). On the basis of the criteria of the 2003 ASRM/ESHRE Rotterdam consensus, PCOS patients were included when diagnosed with two symptoms out of three.

Table II shows the frequency of genotyping in the CYP17A1 gene using TaqMan analysis. However, 7 SNPs, $-600 C>A,-34 C>T,+723 G>A,+2612 T>C,+4259 C>T$, $+4444 C>G$ and $+4994 C>T$ in the $C Y P 17 A 1$ gene showed no association between PCOS patient and normal control groups (Table II). In a previous report, the substitution of $C \rightarrow T$ at -34 bp in the CYP17 gene was higher in a Korean population compared with a Greek population. However, it has been shown that the higher frequency of $A 2 A 2$ genotype has no significant role in hyperandrogenism in women with PCOS (13). Interestingly, our data show a slightly higher frequency of the $A 2 A 2$ genotype in PCOS patients $(n=40,30.08 \%)$ compared with that of controls $(n=25,25.25 \%)$.

We also investigated the association between haplotypes consisting of seven SNPs in CYP17A1 of PCOS patients (Table III). Among haplotypes in CYP17A1, we found five which had a frequency $>0.05$. We analyzed the association between these haplotypes and PCOS using the HapAnalyzer. We found that one of the haplotypes (ht3) was associated with PCOS in a Korean population. Haplotype ht $3(\mathrm{p}=0.001)$ may have a significant association with the pathogenesis of PCOS in a Korean population.

\section{Discussion}

A number of candidate genes for PCOS have been involved in abnormal expression of steroidogenesis. PCOS is characterized by excess androgen secretion and aberrant folliculogenesis causing anovulatory infertility arrest (6-8). One of the candidate genes, CYP17A1, showed elevated expression in PCOS theca cells (15). It has been reported that the position at $-34 C>T$ in $C Y P 17 A 1$ was associated with reduced risk of endometrial cancer (26). Moreover, $-34 C>T$ in CYP17A1 may influence development and progression in prostate cancer (27). Based on previous reports, we investigated whether $-34 C>T$ in the $C Y P 17 A 1$ gene influences the pathogenesis of PCOS. In our study, $-34 C>T$ in $C Y P 17 A 1$ was not associated with PCOS (Table II).

An RFLP study has shown that the substitution of $C \rightarrow T$ at -34 bp in the CYP17 gene is highly associated with PCOS patients in a Korean population compared with a Greek population (19). However, it is indicated that the high frequency of $A 2 A 2$ genotype has a significant role in hyperandrogenism in women with PCOS (13). In the present study, we confirmed that the frequency of $A 2 A 2$ genotype for $C \rightarrow T$ at -34 bp in the $C Y P 17 A 1$ gene is high. Therefore, we suggest that the $A 2 A 2$ genotype of the $C \rightarrow T$ variant at -34 bp in the CYP17Al gene is highly expressed in PCOS patients compared with control subjects. Moreover, an association study using TaqMan sequencing analysis for 6 novel SNPs, $-600 C>A,+723 G>A,+2612 T>C,+4259 C>T,+4444 C>G$ and $+4994 C>T$ in the $C Y P 17 A 1$ gene revealed that there was no significant association (Table II).

In addition to association tests for 7 candidate SNPs in the CYP17Al gene, we performed haplotype analysis (Table III). 


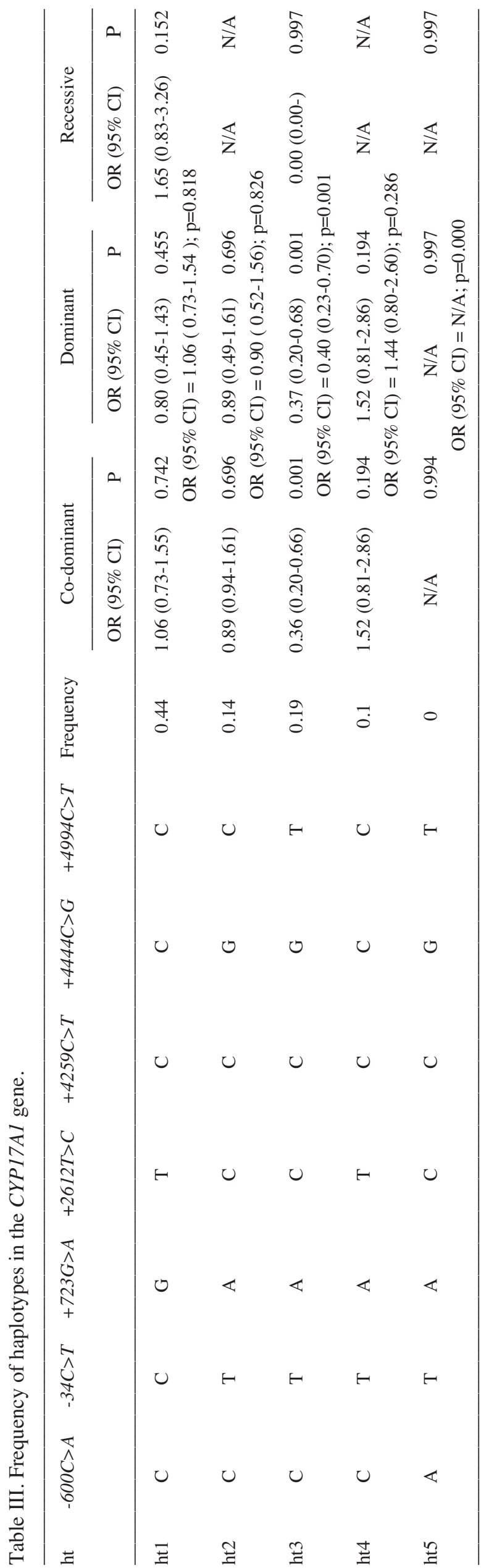

The results indicated that the haplotype ht3 $(\mathrm{p}=0.001)$ is associated with PCOS in this Korean population. However, haplotypes ht1, ht2, ht4 and ht5 are not associated with PCOS. Therefore, ht 3 may be involved in the pathogenesis of PCOS in a Korean population.

It has been previously suggested that PCOS is associated with obesity, insulin resistance and testosterone levels (15). The obesity, LH, and testosterone levels in PCOS groups were two times higher than in control groups when the PCOS patient group was compared with a control group. Moreover, DHEA-S levels showed a slightly higher expression in PCOS subjects. Since the pathogenesis of PCOS is caused by obesity, diabetes and steroidogenesis, various standards are required for sampling methods. Therefore, analyses of further association studies with various aspects of sampling methods are required as PCOS disorder is caused by multiple factors. Moreover, further studies on candidate genes involved in the regulation of hyperandrogenism and/or steroidogenesis in various ethnic populations are required to identify the relation of single nucleotide polymorphisms to the etiology of polycystic ovary syndrome.

\section{Acknowledgements}

This study was supported by a grant from the Korea Health 21 R\&D Project, Ministry of Health and Welfare, Korea (01PJ10-PG6-01 GN13-0002). We would like to thank members of the Fertility Center and the Cell and Gene Therapy Research Institute at Pochon CHA University and CHA General Hospital for their co-operation.

\section{References}

1. Chang WY, Knochenhauer ES, Bartolucci AA and Azziz R: Phenotypic spectrum of polycystic ovary syndrome: clinical and biochemical characterization of the three major clinical subgroups. Fertil Steril 83: 1717-1723, 2005.

2. Pasquali $\mathrm{R}$ and Gambineri A: Polycystic ovary syndrome: a multifaceted disease from adolescence to adult age. Ann NY Acad Sci 1092: 158-174, 2006.

3. Byun EK, Kim HJ, Oh JY, Hong YS and Sung YA: The prevalence of polycystic ovary syndrome in college students from Seoul. J Kor Soc Endocrinol 20: 120-126, 2005.

4. The Rotterdam ESHRE/ASRM-sponsored PCOS consensus workshop group: Revised 2003 consensus on diagnostic criteria and long-term health risks related to polycystic ovary syndrome. Hum Reprod 19: 41-47, 2004.

5. The Rotterdam ESHRE/ASRM-sponsored PCOS consensus workshop group: Revised 2003 consensus on diagnostic criteria and long-term health risks related to polycystic ovary syndrome. Fertil Steril 81: 19-25, 2004.

6. Apridonidze T, Essah PA, Iuorno MJ and Nestler JE: Prevalence and characteristics of the metabolic syndrome in women with polycystic ovary syndrome. J Clin Endocrinol Metab 90: 1929-1935, 2005.

7. Franks S, Gharani N, Waterworth D, Batty S, White D, Williamson R and McCarthy M: Genetics of polycystic ovary syndrome. Mol Cell Endocrinol 145: 123-128, 1998.

8. Sheehan MT: Polycystic ovarian syndrome: diagnosis and management. Clin Med Res 2: 13-27, 2004.

9. Ehrmann DA, Liljenguist DR, Kasza K, Azziz R, Legro RS and Ghazzi MN: PCOS/Troglitazone Study Group: Prevalence and predictors of the metabolic syndrome in women with polycystic ovary syndrome. J Clin Endocrinol Metab 91: 48-53, 2006.

10. Carey AH, Waterworth D, Patel K, White D, Little J, Novelli P, Franks S and Williamson R: Polycystic ovaries and premature male pattern baldness are associated with one allele of the steroid metabolism gene CYP17. Hum Mol Genet 3: 1873-1876, 1994. 
11. Lee EJ, Yoo KJ, Kim SJ, Lee SH, Cha KY and Baek KH: Single nucleotide polymorphism in exon 17 of the insulin receptor gene is not associated with polycystic ovary syndrome in a Korean population. Fertil Steril 86: 380-384, 2006.

12. Lee EJ, Oh B, Lee JY, Kimm K, Lee SH and Baek KH: A single nucleotide polymorphism of INSR gene for polycystic ovary syndrome. Fertil Steril (In press).

13. Lee EJ, Oh B, Lee JY, Kimm K, Park JM and Baek KH: Association study between single nucleotide polymorphisms in the VEGF gene and polycystic ovary syndrome (POCS). Fertil Steril (In press).

14. Hansen L, Ekstrom CT, Tabanera Y, Palacios R, Anant M, Wassermann K and Reinhardt RR: The pro12Ala variant of the $P P A R G$ gene is a risk factor for PPAR $\gamma / \alpha$ agonist induced edema in type 2 diabetic patients. J Clin Endocrinol Metab 91: 3446-3450, 2006.

15. Wood JR, Ho CK, Nelson-Degrave VL, McAllister JM and Strauss JF: The molecular signature of polycystic ovary syndrome (PCOS) theca cells defined by gene expression profiling. J Reprod Immunol 63: 51-60, 2004.

16. Doi SA, Al-Zaid M, Towers PA, Scott CJ and Al-Shoumer KA: Steroidogenic alterations and adrenal androgen excess in PCOS. Steroids 71: 751-759, 2006.

17. Genazzani AD, Lanzoni C, Ricchieri F, Baraldi E, Casarosa E and Jasonni VM: Metformin administration is more effective when non-obese patients with polycystic ovary syndrome show both hyperandrogenism and hyperinsulinemia. Gynecol Endocrinol 23: 146-152, 2007.

18. Lin JF, Li X and Zhu MW: Exploration of the classification of polycystic ovarian syndrome. Zhonghua Fu Chan Ke Za Zhi 41: 684-688, 2006.

19. Lim SK, Kim MS, Lee SH and Baek KH: Polymorphism of CYP17 and CYP11a for polycystic ovary syndrome in a Korean Population. Korean J Genetics 4: 343-348, 2002.
20. Akhtar MK, Kelly SL and Kaderbhai MA: Cytochrome b(5) modulation of 17ahydroxylase and 17-20 lyase (CYP17) activities in steroidogenesis. J Endocrinl 187: 267-274, 2005.

21. Techatraisak K, Conway GS and Rumsby G: Frequency of a polymorphism in the regulatory region of the 17 alphahydroxylase-17,20-lyase (CYP17) gene in hyperandrogenic states. Clin Endocrinol 46: 131-134, 1997.

22. Carmina E, Rosato F, Janni A, Rizzo M and Longo RA: Relative prevalence of different androgen excess disorders in 950 women referred because of clinical hyperandrogenism. J Clin Endocrinol Metab 91: 2-6, 2006

23. Kim J, Park J, Kim S, Choi Y, Shin C, Moon S, Lee J and Chang Y: Clinical study on infertile women with oligomenorrhea. Kor J Obstet Gynecol 38: 824-826, 1995.

24. Gharani N, Waterworth DM, Batty S, White D, Gilling-Smith C, Conway GS, McCarthy M, Franks S and Williamson R: Association of the steroid synthesis gene CYP11a with polycystic ovary syndrome and hyperandrogenism. Hum Mol Genet 3: 397-402, 1997.

25. Dacou-Voutetakis C and Dracopoulou M: High incidence of molecular defects of the CYP21 gene in patients with premature adrenarche. J Clin Endocrinol Metab 84: 1570-1574, 1999.

26. Olson SH, Bandera EV and Orlow I: Variants in estrogen biosynthesis genes, sex steroid hormone levels, and endometrial cancer: a HuGE review. Am J Epidemiol 165: 235-245, 2007.

27. Mononen N, Seppala EH, Duqqal P, Autio V, Ikonen T, Ellonen P, Saharinen J, Saarela J, Vihinen M, Tammela TL, Kallioniemi O, Bailey-Wilson JE and Schleutker J: Profiling genetic variation along the androgen biosynthesis and metabolism pathways implicates several single nucleotide polymorphisms and their combinations as prostate cancer risk factors. Cancer Res 66: 743-747, 2006. 